\title{
Cerebrospinal Fluid Pressure and Prolactin in Empty Sella Syndrome
}

\author{
Giulio Maira, Carmelo Anile, Laura De Marinis, Antonio Mancini and Antonino Barbarino
}

\begin{abstract}
In 58 female patients with the primary empty sella (PES) syndrome, a study of the CSF dynamics was done by evaluating both the absorptive reserve by a lumbar infusion test at constant rate, and/or the ICP increase occurring during REM phase of nocturnal physiological sleep. In 33, prolactin (PRL) dynamics were also investigated evaluating both the response to sequential stimulating test with thyrotropin-releasing hormone (TRH) and metoclopramide (MCP) and/or the circadian variation of PRL levels. Impairment of CSF dynamics was found in the $84 \%$ who had a hormonal pattern characterized by an increase of the PRL response to TRH and MCP and a decrease of the PRL circadian variation. Twenty-one patients with impaired CSF dynamics underwent CSF shunting procedures with disappearance of the signs of intracranial hypertension. They also had restoration of normal PRL dynamics but the endocrine alterations improved only moderately. Altered CSF dynamics play a role in the pathogenesis of the PES syndrome. A correlation between elevated ICP and the hypothalamo-hypophyseal control of PRL secretion may exist.
\end{abstract}

RESUME: Pression du liquide céphalorachidien et prolactine dans le syndrôme de la selle turcique vide Chez 58 patientes, atteintes du le syndrome de la selle vide primaire (SVP), toutes des femmes, nous avons étudié la dynamique du LCR, en évaluant la réserve d'absorption par le test d'infusion lombaire à débit continu et/ou l'augmentation de la pression intracrânienne (PIC) lors de la phase REM (mouvements oculaires rapides) du sommeil nocturne physiologique. Chez 33 de ces patientes, la dynamique de la prolactine (PRL) a également été investiguée en étudiant la réponse au test de stimulation séquentielle à l'hormone de libération de la thyréotropine (TRH) et au métoclopramide (MCP) et/ou les variations circadiennes des taux de PRL. Une altération de la dynamique du LCR a été retrouvée dans $80 \%$ de nos patients: de plus, nous avons trouvé une relation constante avec un type hormonal caractérisé par une augmentation de la réponse de la PRL au TRH et au MCP et une diminution de la variation circadienne de la PRL. Vingt et un patients avec altération de la dynamique du LCR ont subi des interventions de dérivation du LCR avec disparition des signes d'HIC et restitution d'une dynamique normale du LCR. Cependant, les modifications endocriniennes ne furent que modérément améliorees. Nos résultats confirment le rôle d'une perturbation de la dynamique du LCR dans la pathogénie du syndrome de la SVP et suggèrent une corrélation entre la PIC et le contrôle hypothalamo-hypophysaire de la sécrétion de PRL.

Can. J. Neurol. Sci. 1990; 17:92-94

The primary empty sella (PES) is defined as an extension of the subarachnoid space below the diaphragma sella, in subjects who have not previously received surgical or radiotherapic treatment to the sellar region. 1,2

In many cases, particularly in young women, it is associated with slight endocrine disturbances, obesity, hypertrichosis, irregular menses and sometimes galactorrhea. Signs of intracranial hypertension such as headache, visual disturbances and papilloedema ${ }^{3,4,5}$ can also occur. Rarely a spontaneous cerebrospinal fluid (CSF) leakage may occur. ${ }^{6}$

A chronic or intermittent increase of intracranial pressure (ICP) may play an etiologic role in the development and maintenance of PES.7.8.9 The pituitary gland may be pressed against the floor of the sella turcica which could stretch the pituitary stalk. This could explain both the signs of intracranial hypertension and the endocrine symptoms.

Nevertheless little data exists on CSF pressure increases in patients with PES syndrome, and no hormonal pattern has been found to be typical of this syndrome. A correlation between ICP and the hypothalamo-hypophyseal signs of imbalance is not yet established.

\section{Methods and Materials}

In 58 women, in whom an empty sella was radiologically diagnosed by pneumoencephalography, CT scan cisternography or NMR, a study of CSF dynamics evaluated both the absorptive reserve by a lumbar constant rate infusion test ${ }^{10}$ (normal value in our laboratory is $>0.11 \mathrm{ml} / \mathrm{min} / \mathrm{mmHg}$ ), and/or the spontaneous increase in ICP which occurs during the REM phase of nocturnal physiological sleep. ${ }^{11}$ The pressure is recorded through a spinal needle or an intraventricular catheter. Normal values in our laboratory are $<30 \mathrm{mmHg}$. Forty-three of all the patients were in the fertile period and 15 were postmenopausal.

In a selected group of 33 cases, prolactin (PRL) dynamics were also investigated using both a sequential stimulating test with intravenous injection of $200 \mu \mathrm{g}$ of Thyrotropin Releasing Hormone (TRH) followed by the oral administration of $10 \mathrm{mg}$ 
of Metoclopramide (MCP) after 60 minutes and/or the measurement of the circadian variation of the PRL levels recorded with blood samples collected every 2 hours by a cannula inserted in one arm and maintained patent by infusing a saline solution. PRL periodicity was evaluated by comparing the mean PRL levels during waking and sleeping periods. Pituitary function and reserve for the other hormones were also studied and found to be in the normal range in all patients.

The endocrine investigations were repeated in 9 patients of this group who had elevated ICP one week after CSF shunting utilizing either a ventriculo-atrial or ventriculo/lumbo-peritoneal device. The same endocrine tests were compared with the results obtained in two groups of pre- and post-menopausal normal volunteer women whose routine skull $X$-rays showed no major pathology in the sellar region. The subjects in the fertile period were tested during the follicular phase of their menstrual cycles.

All the hormonal data were submitted to statistical analysis by means of the T-test for unpaired groups and expressed in the tables as mean \pm standard deviation.

\section{Results}

\section{CSF dynamics and clinico-hormonal findings}

An impairment in the CSF dynamics was observed in 49 $(84 \%)$ of our patients. The distribution of the most frequent symptoms found in our series is reported in Table 1. There is no significant difference between patients with or without impaired CSF dynamics except for the papilloedema; this sign is always associated with the presence of a defect in the CSF absorptive capacity with increased ICP.

Spontaneous CSF leakage was sometimes observed in patients who did not have a measured impairment in the CSF dynamics.

\section{CSF and PRL dynamics}

Pre- and post-menopausal patients with PES syndrome and altered CSF dynamics show, in comparison to normal range, an increased and prolonged PRL response to TRH and a further increase of PRL levels following MCP administered 60 minutes after TRH injection (Tables 2, 3). This typical pattern is attenuated in premenopausal patients with normal (or normalized after shunting) CSF dynamics in whom the PRL response to TRH is in the normal range at 20 minutes, moderately increased at 60 minutes, but clearly elevated after sequential administration of MCP (Table 2).

Table 1: Correlation between CSF Dynamics and Clinical Findings

\begin{tabular}{llll} 
No. of cases & $\begin{array}{c}\text { All } \\
\text { patients } \\
\mathbf{5 8}\end{array}$ & $\begin{array}{c}\text { Normal CSF } \\
\text { dynamics } \\
\mathbf{9}\end{array}$ & $\begin{array}{c}\text { Impaired CSF } \\
\text { dynamics } \\
\mathbf{4 9}\end{array}$ \\
\hline Headache & $50(86 \%)$ & $8(88 \%)$ & $42(86 \%)$ \\
Visual disturbances & $27(46 \%)$ & $3(33 \%)$ & $24(49 \%)$ \\
Obesity & $26(45 \%)$ & $4(44 \%)$ & $22(45 \%)$ \\
Irregular menses & $23(53 \%)^{*}$ & $4(50 \%)^{*}$ & $19(54 \%)^{*}$ \\
Hypertrichosis & $19(33 \%)$ & $3(33 \%)$ & $16(33 \%)$ \\
Galactorrhea & $14(24 \%)^{*}$ & $4(50 \%)^{*}$ & $10(29 \%)^{*}$ \\
CSF leak & $12(21 \%)$ & $2(22 \%)$ & $10(20 \%)$ \\
Papilloedema & $9(15 \%)$ & - & $9(18 \%)$ \\
\hline
\end{tabular}

*Considering only the 43 patients in fertile period.
Table 2: Correlation between CSF Dynamics and PRL Response to TRH-MCP Sequential Test in Pre-Menopausal PES Patients

\begin{tabular}{|c|c|c|c|c|}
\hline & \multicolumn{4}{|c|}{$\underset{(\mathrm{ng} / \mathrm{ml})}{\text { PRL }}$} \\
\hline & A & B & C & D \\
\hline $\begin{array}{l}\text { Normal } \\
\text { volunteers } \\
\text { (n. 12) }\end{array}$ & $\begin{array}{c}10.18 \\
\pm \\
3.55\end{array}$ & $\begin{array}{c}58.10^{*} \\
\pm \\
12.07\end{array}$ & $\begin{array}{c}13.89^{*} \\
\pm \\
5.89\end{array}$ & $\begin{array}{c}52.14^{* *} \\
\pm \\
14.19\end{array}$ \\
\hline $\begin{array}{l}\text { Normal or } \\
\text { normalized } \\
\text { CSF dynamics } \\
(\mathrm{n} .12)\end{array}$ & $\begin{array}{c}10.64 \\
\pm \\
4.38\end{array}$ & $\begin{array}{c}54.14^{\wedge} \\
\pm \\
28.43\end{array}$ & $\begin{array}{c}23.28 \\
\pm \\
12.50\end{array}$ & $\begin{array}{c}133.80^{\text {水水 }} \\
\pm \\
62.79\end{array}$ \\
\hline $\begin{array}{l}\text { Impaired } \\
\text { CSF dynamics } \\
\text { (n. 17) }\end{array}$ & $\begin{array}{c}12.58 \\
\pm \\
5.85\end{array}$ & $\begin{array}{c}73.70^{* \wedge} \\
\pm \\
28.36\end{array}$ & $\begin{array}{l}32.33^{*} \\
\pm \\
20.36\end{array}$ & $\begin{array}{c}124.30^{* * *} \\
\pm \\
44.33\end{array}$ \\
\hline
\end{tabular}

$A=P R L$ baseline value before TRH injection.

$B=$ PRL value $20^{\prime}$ after TRH injection.

$C=$ PRL value $60^{\circ}$ after TRH injection (at the moment of the MCP oral administration).

$\mathrm{D}=\mathrm{PRL}$ value $60^{\prime}$ after MCP oral administration.

$*$ and ${ }^{\wedge}=$ statistical difference with $P<0.05$.

$* *=$ statistical difference with $\mathrm{P}<0.005$.

Table 3: Correlation between CSF Dynamics and PRL Response to TRH-MCP Sequential Test in Post-Menopausal PES Patients

\begin{tabular}{lcccc}
\hline \hline & \multicolumn{4}{c}{$\begin{array}{c}\text { PRL } \\
(\mathbf{n g} / \mathbf{m l})\end{array}$} \\
& $\mathbf{A}$ & B & C & D \\
\hline $\begin{array}{l}\text { Normal } \\
\text { volunteers } \\
\text { (n. 6) }\end{array}$ & $3.66^{*}$ & $16.30^{*}$ & $9.66^{*}$ & $43.30^{* *}$ \\
Impaired & \pm & \pm & \pm & \pm \\
CSF dynamics & 1.74 & 2.62 & 1.25 & 11.81 \\
(n. 8) & $11.20^{*}$ & $41.15^{*}$ & $24.90^{*}$ & $97.00^{*}$ \\
& \pm & \pm & \pm & \pm \\
\hline
\end{tabular}

$A=P R L$ baseline value before TRH injection.

$B=P R L$ value $20^{\prime}$ after TRH injection.

$\mathrm{C}=\mathrm{PRL}$ value $60^{\prime}$ after TRH injection (at the moment of the MCP oral administration).

$\mathrm{D}=\mathrm{PRL}$ value $60^{\circ}$ after $\mathrm{MCP}$ oral administration

* = statistical difference with $\mathrm{P}<0.005$.

Table 4: Correlation between CSF Dynamics and PRL Circadian Variation in Pre-Menopausal PES Patients

\begin{tabular}{lcc} 
& $\mathbf{W}$ & $\begin{array}{c}\text { PRL } \\
(\mathbf{n g} / \mathbf{m l})\end{array}$ \\
\hline $\begin{array}{l}\text { Normal volunteers } \\
\text { (n. 6) }\end{array}$ & $13.67 \pm 7.77$ & $36.27 \pm 14.02^{*}$ \\
$\begin{array}{l}\text { Normal or normalized } \\
\text { CSF dynamics } \\
\text { (n. 4) }\end{array}$ & $11.23 \pm 5.88$ & $22.59 \pm 7.13^{*}$ \\
$\begin{array}{l}\text { Impaired CSF dynamics } \\
\text { (n. 5) }\end{array}$ & $11.33 \pm 5.38$ & $11.87 \pm 4.74^{*}$ \\
\hline
\end{tabular}

$W=$ mean PRL value during waking period.

$\mathrm{S}=$ mean PRL value during sleeping period.

* = statistical difference with $\mathrm{P}<0.005$. 
Table 5: Correlation between CSF Dynamics and PRL Circadian Variation in Post-Menopausal PES Patients

\begin{tabular}{lcc}
\hline \hline & W & $\begin{array}{c}\text { PRL } \\
(\mathbf{n g} / \mathrm{ml})\end{array}$ \\
\hline $\begin{array}{l}\text { Normal volunteers } \\
(\mathrm{n} .5)\end{array}$ & $11.60 \pm 8.60$ & $\mathrm{~S}$ \\
$\begin{array}{l}\text { Normal or normalized } \\
\text { CSF dynamics } \\
(\mathrm{n} .3)\end{array}$ & $7.97 \pm 2.04$ & $17.72 \pm 3.08^{*}$ \\
$\begin{array}{l}\text { Impaired CSF dynamics } \\
\text { (n. 4) }\end{array}$ & $8.68 \pm 2.52$ & $12.65 \pm 2.71^{*}$ \\
\hline
\end{tabular}

$W=$ mean PRL value during waking period.

$\mathrm{S}=$ mean $\mathrm{PRL}$ value during sleeping period.

* = statistical difference with $P<0.005$.

An absence or blunting of the circadian periodicity of PRL secretion is evident in all patients with abnormal ICP. However, the nocturnal PRL elevation is maintained (or restored) in patients with PES syndrome but normal (or normalized) CSF dynamics (Tables 4,5 ).

\section{Surgical treatment and outcome}

Twenty-one patients with clear clinical and laboratory signs of impaired CSF dynamics (including all with spontaneous CSF leaks) underwent CSF shunting procedures using high resistance devices. Immediately after surgery the signs of increased ICP (headache, visual disturbances, papilloedema and CSF leaks) disappeared. In some cases slight or moderate symptoms due to orthostatic over-drainage became evident but abated after a few days. Endocrine alterations, on the contrary, improved only slightly.

In one of two patients with a spontaneous CSF leak, but without signs of impaired CSF dynamics, a transsphenoidal approach to the sella turcica to repair the sellar floor was carried out because a CT-scan cisternogram had shown the CSF leak from the sella to the sphenoid sinus. In the other patient, without such an evidence, a CSF shunt was performed which relieved the rhinorrhea.

\section{Discussion}

The role of increased ICP in the pathogenesis of the PES syndrome was confirmed. Clinical signs such as papilloedema and CSF leak correlate well with the finding of an actual increase in ICP and are relieved after CSF shunting procedures.

The abnormally elevated $P R L$ response to TRH-MCP sequential stimulation and the absent or blunted PRL circadian periodicity suggest that the endocrine alterations of the PES syndrome could be characterized by an augmented PRL reserve, probably due to an altered dopaminergic control on PRL release. In other words, more PRL hormone is stored in the lactotropes during the day which may be released in greater quantity after appropriate stimulation.

Recent studies have documented that, in normal subjects, dopaminergic antagonist drugs induce considerable additional PRL secretion when injected during TRH infusion, while double TRH stimulation failed to do so. 12 It may be speculated that the increase of PRL during TRH infusion activates, via a short-loop feedback, the dopamine turnover which is antagonized by the antidopaminergic drugs. This hypothesis is also supported by experimental data obtained in rats which have received an intraventricular injection of PRL or which have had a PRL-secreting pituitary tumor implanted subcutaneously. ${ }^{13}$ In such experimental conditions, it has been demonstrated that the concentration of dopamine in the portal plasma is significantly higher than that of control rats.

It is difficult to explain the mechanism which underlies the ICP influence on PRL dynamics. In a selected series of premenopausal women with empty sella, PRL secretion was decreased following oral administration of a dopamine agonist (Nomifensine), this response was reduced in those with impaired CSF dynamics compared to the others. 14

This drug activates dopamine neurotransmission mainly by inhibiting dopamine re-uptake, ${ }^{15}$ which suggests that increased ICP by compressing the pituitary stalk, interferes with dopamine re-uptake thereby enhancing the dopamine activity at the pituitary level and causing a reduced response to nomifensine.

\section{REFERENCES}

1. Kaufmann B. The "empty" sella turcica. A manifestation of the intrasellar subarachnoid space. Radiology 1968; 90: 931-941.

2. Neelon FA, Goree JA, Lebovitz HE. The primary empty sella. Clinical and radiological characteristics and endocrine function. Medicine 1973; 52: 73-92.

3. Davis S, Tress B, King J. Primary empty sella syndrome and benign intracranial hypertension. Clinical and experimental neurology. Proc Aust Assoc Neurol 1978; 15: 248-257.

4. Foley KM, Posner JB. Does pseudotumor cerebri cause the empty sella syndrome? Neurol Minneap 1975; 25: 565-569.

5. Weisberg LA, Housepian EM, Saur DP. Empty sella syndrome as complication of benign intracranial hypertension. J Neurosurg 1975; 43: 177-180.

6. Davis S, Kaye AH. A dynamic pressure study of spontaneous CSF rhinorrhea in the empty sella syndrome. J Neurosurg 1980; 52: 103-105.

7. Anile C, Maira G. "Empty sella" and benign intracranial hypertension: endocrine and CSF dynamic study. In: Miller JD, Teasdale GM, Rowan JO, Galbraith SL, Mendelow AD, eds. Intracranial Pressure VI. Berlin-Heidelberg: Springer-Verlag 1986; 486-490.

8. Maira G, Anile C, Cioni B, et al. Relationships between intracranial pressure and diurnal prolactin secretion in primary empty sella. Neuroendocrinology 1984; 38: 102-107.

9. Kaye AM, Tress BM, Brownhill D, et al. Intracranial pressure in patients with the empty sella syndrome without benign intracranial hypertension. J Neurol Neurosurg Psychiatry 1982; 45: 209 216.

10. Sklar FH, Beyer CW, Diehl JT, et al. Significance of the so-called absorptive reserve in communicating hydrocephalus: a preliminary report. Neurosurgery 1981; 8: 525-530.

11. Rossi GF, Maira G, Vignati A. Intracranial pressure during sleep in man. In: Levin P, Koella WP, eds. Sleep 1974. Basel: S. Karger AG 1975; 169-180.

12. Mongioi A, Aliffi A, Vicari E, et al. Down-regulation of prolactin secretion in men during continuous thyrotropin-releasing hormone infusion: evidence for induction of pituitary desensitization by continuous TRH administration. J Clin Endocrinol Metab 1983; 56: 904-907.

13. Cramer OM, Parker CR, Porter JC. Secretion of dopamine into hypophyseal portal blood by rats bearing prolactin-secreting tumors or ectopic pituitary glands. Endocrinology 1979; 105: 639-640.

14. Barbarino A, De Marinis L, Mancini A, et al. Prolactin dynamics in normoprolactinemic primary empty sella: correlation with intracranial pressure. Hormone Res 1987; 27: 141-151.

15. Hunt PM, Kannengieser H, Raynaud JP. Nomifensine: a new potent inhibitor of dopamine uptake into synaptosomes from rat corpus striatum. J Pharmacol 1974; 26: 370-371. 